\title{
EUCARÍSTICO DE PAULINO DE PELA
}

\author{
Raúl Lavalle*
}

\section{Introducción}

Conocemos a Paulino de Pela por su poema Eucarístico, que compuso en 459 , cuando tenía más de ochenta años. ${ }^{1}$ Había nacido en la ciudad de Pela, en Macedonia, donde su padre era prefecto. Después fue nombrado procónsul en África, y su hijo fue con él a Cartago. Un año y medio más tarde fue a Roma, y luego a Burdeos, patria de antepasados suyos. Allí conoció a su abuelo, entonces cónsul. Se trataba del poeta Décimo Magno Ausonio, quien en 379 desempeñó esa alta función.

El Eucarístico es un poema autobiográfico de acción de gracias a Dios; unas pequeñas "confesiones" poéticas. En él hace un resumen de su existencia y encuentra en la misericordia divina la explicación de cuanto le pasó en ella.

Su vida agradable de rico galorromano se vio sacudida cuando los godos invadieron el Imperio, y concretamente sus tierras. Las peripecias cercenaron muchísimo su patrimonio. Hacia los cuarenta y seis años tuvo una conversión espiritual, aunque Paulino no había sido, a lo que parece, un gran pecador, un cúmulo de maldad. Perdió luego a su suegra, a su madre, a su mujer y a un hijo. De todos sus bienes poco le quedaba. Gracias a ese poco estuvo un tiempo viviendo en Marsella y luego volvió a Burdeos, donde un godo le dio una suma de dinero por un dominio que antes había pertenecido a Paulino; esto lo puso a salvo de una vejez miserable.

Mi traducción no es literal. Al ser en verso, sé que incurro en un grave riesgo, por mis limitadas condiciones para versificar y por lo difícil y cargado del estilo del autor. No obstante creo que es preferible producir en el lector la

* Catedrático de Filologia grego-latina da Pontifícia Universidade Católica Argentina - Buenos Aires.

1 Los datos biográficos los tomo de: LABRIOLLE, Pierre de. Histoire de la littérature latine chrétienne. Paris: Les Belles-Lettres, 1924. p. 626-629. 
sensación de poesía, por más deficiente que sea la pluma de quien traduce. Me parece que asiste a mi tarea el mérito de poner a disposición del público un documento del mundo galorromano tardo-antiguo, no tan conocido en nuestro medio. Era un ámbito cultural que dio importantes escritores: Ausonio, Sidonio Apolinar y Paulino de Nola, entre otros. El texto sigo es el de Hugh G. Evelyn White. ${ }^{2}$

\section{EUCARÍSTICO de PAULINODE PELA}

\section{Prefacio}

(1) Sé que algunos de los hombres ilustres, para esplendor de sus virtudes y para perpetuar la dignidad de su gloria, han entregado al recuerdo, escritas con propias palabras, las memorias ${ }^{3}$ de sus acciones. No es una justa razón la que me ha movido a urdir una obrita de semejante materia, pues estoy tan alejado de los excelentes méritos de tales hombres como de su antigüedad. En efecto, ni he hecho cosas tan espléndidas como para obtener alguna pequeña gloria con ellas, ni tengo tanta confianza en mi elocuencia como para poder emular la obra de cualquier escritor. (2) Sin embargo - no me da vergüenza confesarlo - la divina misericordia me ha movido, como confío, a buscar estos consuelos, a mí que estoy, ya hace tiempo en largo peregrinar, como marchito por la pesadumbre de un triste ocio $;{ }^{4}$ consuelos que convienen a una vejez que tiene conciencia de sí misma y a un religioso propósito. Tengo conciencia de que debo toda mi vida a Dios y deseo atribuir a su dirección también los actos devotos de toda mi vida y, si su gracia me concede los tiempos, dedicarle un opúsculo eucarístico ${ }^{5}$ bajo la forma de relato de memorias. (3) Sé en verdad que su divina misericordia ha estado cerca de mí, porque tampoco carecí en mi primera edad de los placeres momentáneos concedidos al género humano. Sé

2 Se lo encuentra en el II vol. de la ed. de Ausonio en la colección Loeb: London - New York: William Heinemann - G. P. Putnam's Sons, 1919.

3 El latín usa la palabra griega ephemeridem, cuya raíz da la idea de "diario", "las efemérides".

4 En el latín el texto es igualmente cargado: aerumnosi otii maerore marcescentem.

5 En el sentido etimológico de "acción de gracias". 
también que en esta parte me ayudó el cuidado de su providencia pues él, ejercitándome moderadamente con frecuentes adversidades, evidentemente me enseñó a no amar demasiado la felicidad presente, la cual sabía yo que podría perder; y a no asustarme mucho ante las dificultades, en las cuales había comprobado que sus misericordias podrían asistirme. ${ }^{6}$

(4) Por tanto, si alguna vez este opúsculo mío llega a manos de alguien, a partir de su propio título debe ver que esta pequeña meditación, ofrecida a Dios omnipotente, la destino más a mi ocio que a negocio ${ }^{7}$ ajeno; y es más mi deseo que este servicio mío, valga lo que valga ${ }^{8}$ sea más agradable a Dios que, como poema sin adorno que es, llegue a conocimiento de gente más docta. (5) Pero acaso alguien más curioso tenga suficiente ocio de sus ocupaciones como para conocer el esforzado decurso de mi vida; si encuentra quizás algo o nada para valorar en mis versos o en mis acciones, le ruego que lo que elija lo dé al olvido, antes que encomendarlo al juicio de la memoria.

\title{
Eucarístico a Dios, siguiendo el hilo de mis memorias
}

\author{
Disponiéndome a narrar el tiempo transcurrido \\ de mis años y poner en serie los hechos de mis días, \\ que corrieron vividos por mí con diversa suerte, \\ a ti te suplico, mi Dios omnipotente, que plácido \\ me asistas y que inspires un intento que te agrada; \\ que concedas fruto a mis escritos y a mis deseos \\ provecho, para que con tu ayuda recuerde tus dones. \\ Pues te debo a ti todos los tiempos de mi vida, \\ desde que recibí el primer soplo de la luz vital; \\ si bien a menudo me sacudieron diversas tormentas \\ 10 \\ del inestable mundo, envejecí bajo tu protección \\ y, en el curso de la duodécima semana de mis años,
}

6 En el texto latino hay un largo pasaje, que comienza en "No es una justa razón" (1); lo he cortado con la puntuación. Por otra parte, en el final parece haber una suerte de lectura cristiana del tópico de mantener una "mente igual", tanto en las cosas adversas como en las prósperas (Horacio, Odas 2, 3).

7 Negotium, en sentido de "ocupación".

8 Qualecumque, palabra que usa Catulo en el primer poema de su libro, también para tomar distancia de su obra. 
vi en ella seis ardientes solsticios del estivo sol y otros tantos fríos de la bruma - con tu gracia, Dios, quien restauras los años del tiempo pasado y los renuevas, en el curso de las edades que giran. Séame por eso lícito cantar tus dones con mi verso y corresponder con mis palabras dándote gracias: sabemos en verdad que, encerradas en el corazón, son manifiestas a ti, pero la voz rompe los arcanos de mi mente y abre la fuente de su abundante deseo. ${ }^{9}$ Yo era lactante y tú diste a mi débil cuerpo fuerzas para soportar los duros azares del camino y del mar. Nací en Pela, en la cuna del antiguo rey Alejandro, cerca de los muros de Tesalónica; mi padre cumplía con las funciones de ilustre prefectura. ${ }^{10}$ Fui llevado yo a las tierras, separadas por el mar, de otro mundo, entregado a los temblorosos brazos de las nodrizas, a través de nevadas cumbres y de Alpes cortados por torrentes, a través del océano y aguas del Tirreno.

Vine a las murallas de la sidonia Cartago, ${ }^{11}$ antes que el mes lunar, con renovada luz, hubiera completado el círculo de su novena órbita, desde mi nacimiento. Allí, según supe, transcurridos dieciocho meses, bajo el proconsulado de mi padre, nuevamente me llevan al mar y a los caminos recorridos, a ver las ilustres murallas de la clara Roma, en las cumbres del mundo. ${ }^{12}$ Estas cosas se presentaron ante mí, pero no podían aún ser comprendidas por mi mente; las descubrí después, gracias a las frecuentes relatos de quienes las conocían, y pensé que debía incluirlas en mi obra. Al fin, llegado el término de mis largos caminos, vine

9 En el original hay una imagen del agua: fontem exundantis voti vox conscia prodit.

10 Patre gerente vices inlustris praefecturae. Evelyn White dice que el Padre de Paulino era tal vez un vicarius del Prefecto de Macedonia; pero aclara que otra traducción podría ser simplemente: "performed the functions of the illustrious Prefect."

11 En realidad Cartago fue colonia de Tiro, no de Sidón, aunque ambas eran ciudades fenicias.

12 Visurus et orbis / inclita culminibus praeclarae moenia Romae (v. 36-37). Los elementos se pueden ordenar de más de un modo. P. ej.: "las murallas de la ilustre Roma, célebres por las cumbres del mundo"; vale decir: "on the heights which dominate the world" (Evelyn White, quien admite: "the expresión is very obscure"). 
a la patria de mis mayores, llegué a aquellos techos de mis ancestros, a Burdeos. A sus murallas el bello Garona conduce aguas que le da el reflujo del Océano, por un puerto llenos de naves, que aún hoy encierra un amplio puerto en los muros de una amplia ciudad. ${ }^{13}$ Allí por primera vez conocí a mi abuelo, el cónsul en ese año, durante el primer trienio de nuestra vida. ${ }^{14}$ Después que este fue completado y que el creciente vigor afirmó mis débiles miembros, y que mi mente, dueña de su sentido, se acostumbró a conocer el uso de las cosas, es necesario que revele lo que, de propia fe mía pude ya recordar [...] acerca de mí mismo. ${ }^{15}$ ¿Pero qué otra cosa de aquellos años de mi niñez, los cuales la libertad, los juegos y también una edad más alegre pudieron hacerme gratos, me animaría yo mismo a recordar con más gusto o con más justicia incluir en este librito que compongo en versos, sino toda la piedad y la gran preocupación de mis padres? Este afán sabía siempre mezclar las enseñanzas con los halagos; con sabia solicitud me gobernaban y me inculcaban las bases de las buenas costumbres, de modo que mi rudo ingenio tuviera rápido provecho: pues entre los primeros elementos del propio alfabeto consideraba los diez signos especiales de la ignorancia, ${ }^{16}$ y aprendía a evitar los vicios de la ausencia de sentido. ${ }^{17}$ Aunque hace ya mucho tiempo que cayó en desuso el cultivo de esas disciplinas, por vicio de la época, confieso que las costumbres romanas que conservé

13 La repetición "amplio/amplia" está en el original: quae portum spatiosum / nunc etiam muris spatiosa includit in urbe (v. 45-47). Burdeos está sobre el Garona. Este desagua en el Atlántico; por su amplia boca entraba y salía, según las mareas, el agua del Océano. Ausonio decía lo mismo: el río, surcado por naves, alimentado por fuentes y por el océano, parece un mar: Per mediumque urbis fontani fluminis alveum, / quem pater Oceanus refluo cum impleverit aestu, / adlabi totum spectabis classibus aequor (Ordo urbium nobilium, 145-147).

14 Ausonio fue cónsul en 379.

15 En el original falta una palabra: quidquid iam [...] potui meminisse, necesse est (v. 53).

16 Alusión a los diez mandamientos, que tienen formulación negativa: "no harás esto."

17 Vitia a)koinono/hta. Como vemos, el original trae en griego este adjetivo, ya usado por Aulo Gelio (12, 12). En cuanto a "ignorancia" del verso anterior, Paulino escribe en latín amathiae, palabra griega que tiene un elemento privativo (a-) y las raíces "común" y "mente". 
me agradan, y que por ellas es más tolerable la vejez. Apenas había cumplido el tiempo de mi primer lustro y ya me obligaban a leer las doctrinas de Sócrates, las ficciones bélicas de Homero y aquellos recorridos de Ulises. Inmediatamente me mandan leer libros de Marón ${ }^{18}$ sin haber aprendido bien el latín, pues estaba acostumbrado a esclavos griegos, con quienes larga familiaridad había mantenido en todos mis juegos. Por eso, lo admito, mi esfuerzo mayor fue aprender la elocuencia de los libros de una lengua desconocida. Este doble conocimiento es conveniente para ingenios mejores y adorna con ambos esplendores a los sabios, pero esa división, según ahora pienso, fácilmente dejó exhausta la débil vena de mi muy estéril mente. Esto es lo que ahora, a mi pesar, mostrará esta página mía, poco reflexiva, que expongo para que la lean, que me dará vergüenza a mí, según espero, pero no a las cosas que intentaré exponer en estos escritos. Pues el diligente cuidado de mis castos padres de tal modo, ya de niño, me instruyó, que mi fama no temía ningún daño por los dichos siniestros de cualquiera. Aunque esta bien ganada fama obtuvo su merecido honor, con una honra todavía más grande me habría adornado si los deseos de mi padres ese primer tiempo se hubieran mantenido concordes con los míos; si ellos me hubieran reservado ya de niño para ti, oh Cristo, constantemente, con este cuidado de piedad hacia mí, para que, libre yo de los presentes encantos de la carne, pudiera tener los frutos eternos en el tiempo venidero. ${ }^{19}$ Pero ya ahora es justo que crea que fue conveniente para mí aquello que tú demostraste haber querido, Dios omnipotente y eterno, que todas las cosas gobiernas: a pesar de mis manchas renovaste mis dones vitales. Pues tanto las mayores gracias te debo en mi favor, cuanto reconozco la culpa de mis mayores errores. une vocation religieuse précoce, la contrarièrent dans la suite" (Pierre de Labriolle, p. 628). 
Incauto, hice cosas culpables, y también cosas ilícitas, mientras iba errante por el lábil tiempo de mi vida; pero sé que por tu indulgencia puedo ser del todo perdonado. Así, detesté mis caídas y acudí a tus leyes $\mathrm{y}$, si alguna vez pude precaverme de hacer pecados que, una vez cometidos, me habían dado mayor culpa, sé que esto también lo he conseguido por un don divino. Pero vuelvo a la serie y a aquellos tiempos pasados de esa edad en que, dedicado a los estudios de las letras, me parecía que iba a realizar, con gusto, mis deseos de conseguir algún provecho en mi constante trabajo, con gran cuidado de mi maestros, el argivo y el del Lacio. ${ }^{20}$ Y habría conseguido quizás también un fruto digno, si no hubiera cortado de repente mis proyectos una aguda fiebre cuartana, que impidió los gratos intentos de mis estudios, apenas completado ya el quinto tercio de nuestra vida. ${ }^{21}$ Quedaron muy consternados por mí mis piadosos padres; a ellos les pareció más importante la curación de nuestro vacilante cuerpo que la instrucción en una lengua docta, pues así primero les aconsejaron los médicos, de modo que yo viera constante alegría y todas las cosas gratas al ánimo. Mi padre se esmeró tanto en disponer esto por sí mismo que, si bien él acababa de abandonar su afición por la caza (en verdad, la causa de ello fueron solamente mis estudios: no quería entorpecerlos haciéndome partícipe de sus juegos ni tampoco quería, nunca, disfrutar sin mí de tales placeres), la retomó por mí con mayor cuidado y se ocupó de renovar todos los medios para la práctica de estas diversiones, por medio de las cuales podría recobrar la deseada salud. Al extenderse bastante estos juegos por el largo tiempo de mi enfermedad, me produjeron luego una continua desidia para el estudio, que luego iba a durar, ya sano; tras ella sobrevino un amor nuevo por el mundo falaz, que tuvo la complacencia del gran afecto de mis padres, a quienes bastaba el sentirse alegres porque tenía salud. 
Nuestro error aumentó y creció por este motivo, al ser así fácilmente incitado a seguir mis deseos juveniles: tener para mí un bello caballo y adornado de fáleras, ${ }^{22}$ un alto escudero, ${ }^{23}$ un perro veloz, un hermoso halcón; también una pelota dorada, recién traída de la ciudad de Roma para que, lanzada, sirviera ella a mis juegos; tener, en fin, siempre vestido nuevo y arreglado y toda cosa nueva perfumada con suave olor de mirra árabe. Y no menos me agradaba correr vivamente, llevado en veloz corcel; pero siempre que recuerdo las veces que evité graves caídas, es bueno que piense que fui salvado gracias a tus dones, Cristo. Y debo dolerme: no lo supe entonces, cercado por encantos del mundo. Fluctuando entre ellos y los deseos de mis padres, que constantemente pensaban en mi descendencia, ya casi tarde, según el tiempo de mi vida, me lancé ardiente a nuevos gozos de mi desenfreno juvenil; de estos antes, joven, pensaba que podía guardarme. Sin embargo, en cuanto nuestra lasciva licencia pudo ser retenida por el freno de una cauta moderación, para no acumular sobre mis culpas graves delitos reprimí mis inclinaciones conteniéndolas con esta ley: no buscar jamás a nadie contra su gusto, ni a ninguna de derecho ajeno, y guardar memorioso mi caro pudor; no ceder ante las mujeres libres que se ofrecieran espontáneamente y contentarme con gozar, en casa, de amores serviles. Así, prefería ser reo de una culpa antes que de un delito, porque temía dañar mi nombre. Pero ni siquiera callaré, entre mis acciones, esta: supe que había nacido de mí un hijo en aquel tiempo, pero ni a él lo vi entonces, puesto que en seguida murió, ni a ningún otro que me haya nacido espurio, cuando la libertad, unida a los encantos de la lasciva juventud, podrían muy bien haberme dañado más gravemente, Cristo, si no hubieras tenido entonces cuidado de mí. 
Semejante vida, desde alrededor de los dieciocho años, duró hasta completar dos decenios; entonces contra mi voluntad - lo confieso - el piadoso cuidado de mis padre me obligó a abandonar las costumbres dulces de este estado y a convertirme en el marido de una esposa cuya casa era sin duda más magnífica por su antiguo nombre que por lo que podía agradar poseída entonces: víctima de grandes dificultades, descuidada por mucho tiempo por la senil desidia de su amo, a quien sucedió, sobreviviendo a su padre, una pequeña nieta, que consintió en recibir mis teas. ${ }^{24}$ Mas no bien determiné aceptar la labor impuesta, favoreciendo a mi ánimo el fervor de la juventud, en pocos días me contenté con los gozos de la casa que había ganado y obligué a mi ocio, mal consejero, a adoptar hábitos desacostumbrados; y me forcé a mí mismo y a los míos - a los que pude, con el ejemplo de mi labor; a otros, a su pesar, con el vigor del mando. Y así me dediqué sin pereza a los actos de mi actual estado. Me apresuré a trabajar y a cultivar los campos, a dar un rápido cuidado a los cansados viñedos, una vez conocido por mí el modo para renovarlos; además - lo cual a la mayoría les parece algo muy amargo espontáneamente pagaba yo primero mis impuestos fiscales en tiempo determinado. Así me aseguré ocio, que podría dedicar después a mi particular descanso. Este ocio fue siempre muy querido por mí y coincidía primero con mi natural, que deseaba lo moderado; ${ }^{25}$ pero después, por la molicie y la ambición, fue dejado de lado, y deseaba para mí una lujosa casa con amplias habitaciones y apta para todos los tiempos del año, ${ }^{26}$

24 Las teas nupciales. (Odas 2, 10, 5)

25 Ingenio [...] mediocria desideranti parece un eco de Horacio: la célebre "dorada medianía"

26 "i. e. The house was to be equipped with summer and winter quarters - the latter heated by hypocausts such as may be seen in the existing remains of the more important Roman houses" (Evelyn White). Un ejemplo podría ser la villa, en el Laurentino, de Plinio el Joven, que el propio Plinio describe en sus cartas $(2,17)$. 
de una mesa brillante, con muchos y jóvenes siervos, mobiliario abundante y agradable para diversos usos, también con plata mejor en valor que en peso, artífices expertos en varias artes y rápidos en cumplir lo mandado; con establos repletos de animales bien alimentados y con hermosos carruajes que me llevaran con toda seguridad. Pero no estaba yo demasiado atento a acrecentar estas cosas sino más bien a conservarlas, ni era muy deseoso de aumentar mis bienes ni de ambicionar los honores; más bien - lo confieso - era un buscador de los placeres, si ellos podían conseguirse con exiguo precio y gasto y si ello no menoscababa en nada mi fama y decoro, para que ningún lujo manchara mi irreprochable afán. Yo recibía con gozo y agrado todas estas cosas, pero era mayor en mí una piedad muy grande por mis padres: me ataba a ellos con el lazo de un amor dominante, tanto que la mayor parte del año mi presencia estaba al servicio de ellos; esta estancia coincidía con nuestros deseos y recogía el fruto común de los gozos mutuos. ${ }^{27}$ ¡Ojalá este género de vida, concedido por bondadoso don de Cristo, hubiese permanecido por largo tiempo, durando también entonces las épocas de antigua paz! De muchos modos el frecuente trato y la consulta con mi padre habría aprovechado a nuestra juventud, mi instrucción habría crecido en sus buenos ejemplos. Pero, después que pasaron tres decenios de nuestra vida, siguió un triste preocupación, de un doble peso: uno público, ante la desgracia común de los enemigos que invadieron las propias entrañas del romano reino; otro, privado, fueron los funerales de mi padre muerto, pues los últimos tiempos del final de su vida coinciden casi con los tiempos de la ruptura de la paz. Los daños empero que recibió mi casa, saqueada por los enemigos, aun grandes de por sí, fueron en verdad mucho menores comparados con el enorme dolor por mi padre difunto: 
por él tanto mi patria como mi casa me eran queridos. En verdad con tantas muestras mutuas de fiel afecto vivimos nuestros días en perfecta unión, que nuestra concordia superaba el amor por nuestros coetáneos.

Así un querido compañero de fieles consejos me fue quitado en tiempos de mi primera juventud, pero en seguida surgió la amarga discordia de mi indócil hermano, que intentaba disolver el fuerte testamento de mi padre, con ánimo de impugnar los especiales beneficios de que gozaba mi madre. Por eso, por ser justa, mayor era mi preocupación de cuidarla: afecto no menor de piedad confirmaba mi honesto propósito. Además la desafortunada fama de todos mis recursos me expuso al riesgo de diversas dificultades, entre tentadores encantos de la vana ambición y, al mismo tiempo, los daños provenientes de graves peligros. Aunque no me alegra recordar esto y yo preferiría que quedara mucho tiempo adormecido en el olvido, no obstante, Cristo, el consuelo de tus buenos dones, 260 concedidos en el medio de adversidades, me invita a revelar y a dar a luz lo escondido en mi corazón, pues alcancé tus favores, en el curso de mis males. Y por mi experiencia aprendí fácilmente cuántas cosas la gracia de los poderosos me concedió, por ti: a menudo, sin saberlo, era comparado con el honor glorioso de mis ancestros, antes de que adquiriera yo el mío propio; y cuánto me perjudicaron, atacándome con fuerza maligna, mis abogados con su codiciosa conducta, además de los propios honores que tenía. Y, más que a todos, en especial a mí, que tenía otra patria en una parte del este (en ella había nacido y no parecía el último propietario), los males me echaron mano, mas lo merecía de tiempo atrás. Me debí ausentar y largo tiempo, primero por la propia pereza de mi comitiva, a veces por los pareceres distintos de mis seres queridos, pero muy a menudo porque su ánimo luchaba con mis propios deseos, pues su recurrente temor a posibles adversidades demoraba, 
oponiéndose la suerte, los preparativos de regreso.

$\mathrm{Al}$ revés, halagaban mi ánimo el gusto al descanso, el habitual ocio y las numerosas comodidades de una casa llena, jay!, de molicie, delicias y bienes de toda clase en un tiempo muy duro; una casa que era la única que carecía entonces de huésped godo.

Después esto dio paso a un desafortunado hecho, pues ningún derecho especial protegía mi casa y ella fue presa del pueblo que se retiraba ${ }^{28}$ : pues sabemos que algunos godos, con mucha humanidad, trataron de favorecer a sus huéspedes protegiéndolos. ${ }^{29}$

Pero a esta suerte que acabo de narrar se añadió otra nueva, causa también de mayores problemas. El tirano Átalo, ${ }^{30}$ buscando vano consuelo, me cargó en ausencia mía con un vacío honor; me nombró conde de privada magnanimidad: ${ }^{31}$ sabía él que tal dignidad se sostiene sin recursos. Y ya había perdido confianza en su reino, pues él dependía solo de los godos pero de ellos tenía mala experiencia; podían serle útiles en ese momento para conservar su vida, pero no para que conservara su poder: por sí mismo él no tenía el apoyo de ninguna riqueza propia ni tampoco disponía de soldado alguno. Por eso, digo, de ningún modo seguí la causa de un débil tirano, sino la paz de los godos, que entonces deseaba el consenso de los propios godos, y fue otorgada poco después a otros mediante pago. Pero no hay motivos para arrepentirse, pues vemos que en nuestro estado ya muchísimos florecen gracias al favor de los godos; aunque muchos antes tuvieron que padecer cosas tristes,

28 Es muy literal nuestra trad. de populo abeunti. La de Evelyn White, más interpretativa, vierte "the retiring horde."

29 No encuentro muy clara la redacción de esta parte. Al parecer, Paulino y su familia debieron ausentarse temporalmente; los suyos tenían temor de volver, por las invasiones; él, por otra parte, quería hacerlo pues extrañaba las comodidades de su casa. Esta ausencia favoreció el pillaje, al que se refiere el v. 288.

30 "Priscus Attalus was an Ionian and originally a Pagan. He was a Senator and Praefect of the city at the second siege of Rome. He was set up as puppet Emperor by the Goths, but deposed in $410 \mathrm{~A}$. D. He remained in the company of Ataulf the Goth, at whose wedding with Placidia he performed as a musician. During the revolt of Jovinus he was again set up as a rival Emperor, but was soon abandoned, and in $416 \mathrm{~A}$. D. was banished by Honorius to Lipari" (nota de Evelyn White).

$31 \mathrm{O}$ sea Comes Privatarum Largitionum. 
y uno de ellos fui yo, que me encontré privado de todos mis propios bienes y fui un sobreviviente de mi patria.

Pues los godos estaban, por orden de su rey Ataúlfo, ${ }^{32}$

por irse de la ciudad, donde en paz ellos habían sido recibidos, como si nos hubieran sometido en guerra, quemaron la ciudad y nos maltrataron de toda forma. Y como me hallaron conde de aquel príncipe a cuyo poder no se consideraban asociados, me despojaron de todos mis bienes y, al mismo tiempo, a mi madre, reunidos así ambos bajo suerte común: en esto solo creían que se apiadaban de nosotros, cautivos, en que nos permitían partir a salvo de cualquier otro daño. Al tiempo, de todas las acompañantes y servidoras que habían seguido nuestros azares quedó en salvo su pudor, sin que atentara nadie en contra de ellas; yo me vi aliviado, por mi parte, de más graves males, por don de Dios y a él debo perennes gracias: mi hija había sido unida antes por mí a un marido y, al estar fuera de nuestra patria, no tuvo la desgracia común. $Y$ esta que digo no fue la última meta ${ }^{33}$ de los trabajos que soporté, pues no bien nos echaron de los lares paternos y de nuestros quemados techos, el asedio del enemigo nos tomó también en Vasatas, ${ }^{34}$ ciudad vecina, que era la propia patria de mis mayores. ${ }^{35}$ Y mucho más grave que los enemigos alrededor fue una facción de esclavos unida al insano furor de ciertos jóvenes malvados, aunque eran libres, que se habían armado, sobre todo para matar nobles. Justo Dios, alejaste de mi sangre inocente esa muerte y, con la de unos pocos acusados, la calmaste pronto;

32 "Alaric's brother-in-law, who brought reinforcements of Goths and Huns to aid Alaric in 409 A. D. In 410 he became King of the Visigoths on the death of Alaric. Later he married Placidia, sister of Honorius, and was murdered at Barcelona [...] The name Ataulf survives in the modern Adolf" (nota de Evelyn White).

33 Paulino toma aquí meta en el sentido de "fin", no en el más antiguo, del mojón alrededor del cual se giraba en el circo.

34 Vasates o Vasatae es el nombre de un pueblo y de una ciudad sobre el río Garona. Castellanizo a partir de la segunda forma.

35 Julio Ausonio, padre del poeta Décimo Magno Ausonio y abuelo de Paulino de Pela, había nacido allí, según se desprende de Poemas domésticos, de Ausonio (“Epicedio a su padre”, v. 1-4). 
$y$, sin saberlo yo, ordenaste que el ejecutor especial destinado a mí pereciera a manos de otro vengador, pues acostumbrabas atarme a ti con nuevos dones, por los cuales supiera que te debía perennes gracias. Para mí, sacudido ante la suerte de un tan repentino peligro, por el cual veía que podía ser herido dentro de la ciudad, me vino a la mente, por mi gran temor, un nuevo error: que con ayuda del rey tanto tiempo querido por mí, ${ }^{36}$ cuyo pueblo nos oprimía con largo exilio, podría escapar de la ciudad sitiada, con gran número de todos mis seres queridos. Una esperanza era la que movía este intento nuestro, pues yo sabía que, obligado él por el mandato de toda la multitud de godos, a su pesar el rey agobiaba a nuestro pueblo. Por eso, con afán de averiguar, intrépido me alejé de la ciudad y fui hasta el rey, y nadie me lo impidió; pero más contento que antes de hablarle a mi amigo, al cual - pensaba - le resultaría agradable. Después al descubrir, cuanto pude, sus íntimos cuidados, negó que me pudiera prestar ayuda ninguna si yo estaba fuera de la ciudad: pues no estimaba seguro para él que yo, una vez visto, volviera a la ciudad, a no ser 360 que fuera recibido conmigo en la ciudad, ${ }^{37}$ pues sabía que los godos de nuevo me amenazaban con cosas terribles, y él a su vez quería liberarse de su poder. Confieso mi estupefacción y miedo por la condición propuesta y por el terror al peligro indicado, mas 365 se compadeció Dios, quien siempre y en todo lugar se muestra a los que lo invocan; recuperé pronto mi ánimo, aunque todavía temía, y seguí el consejo de mi vacilante amigo; rechacé las cosas difíciles que sabía serían negadas por completo y más busqué 355 lo que urgía que lo que después debería aventurar. De inmediato este hombre prudente siguió el parecer y luego de consultar con los principales de la ciudad se apresuró y en una sola noche, gracias a Dios, cuya

37 Esta repetición de la palabra "ciudad" está en el original: extra urbem, ad urbem, in urbe. 
ayuda ya tenía, hizo lo necesario para poder ayudar

no solo a nosotros sino también a todo su pueblo.

Acudió al mismo tiempo de todas partes la multitud toda de mujeres alanas, junto a sus maridos en armas. ${ }^{38}$ La esposa del rey es entregada primera como rehén a los romanos, acompañada del querido hijo del rey, y soy devuelto a los míos como parte de la pactada paz, como salvado del enemigo común, los godos; los límites de la ciudad son vallados con soldados alanos, tomada y dada la fe de pelear por nosotros, a quienes poco antes habían sitiado como enemigos. Rara se veía la ciudad, cuyos muros inermes rodea por todas partes turba de uno y otro sexo, que yacía afuera; columnas de bárbaros que asían nuestros muros son vallados tanto por carros como por armas. Pero la turba de los godos, que alrededor devastaban todo, se vio privada de parte no pequeña del ejército y al punto desesperó de poder permanecer a salvo, no bien su aliado interno se volvió contra sus propias entrañas; no intentó nada más y prefirió alejarse espontáneamente. Este ejemplo siguieron en seguida nuestros aliados, aquellos que ya dijimos sin embargo también se alejaron, aunque listos para guardar la fe de paz con los romanos, si la suerte los llamaba a ello. Y así algo comenzado por mí de una manera azarosa fue cumplido, con el auxilio divino, de modo favorable y Dios transformó mi error en nuevos gozos, levantado el asedio que pesaba sobre mí y sobre muchos otros; todo esto se suma para darte las gracias a ti, Cristo, a quien soy incapaz de retribuir, pero de alguna forma por las palabras las pago, pues confieso lo que te debo. Pero baste lo dicho por mí acerca de todas estas cosas que padecí, largo tiempo, expuesto entre los pueblos bárbaros. Por ellos a menudo experimenté muchas adversidades, que de nuevo me persuadieron, a mí

38 "The army besieging Bazas was partly of Goths and partly of Alans. The latter, headed by Ataulf, went over to the Roman side and prepared to defend the city against the Goths" (nota de Evelyn White). 
que me demoraba, a dejar lo antes posible las patrias moradas - haberlo hecho antes habría sido más útil y dirigirnos con sostenido curso a aquellas costas donde todavía una gran parte del patrimonio materno estaba a salvo, esparcida por muchas ciudades argivas y del Epiro, tanto del Viejo como del Nuevo. ${ }^{39}$ Tenía allí predios no pequeños, llenos de muchos labriegos, separados pero no en exceso alejados uno de otro, que habrían bastado, en su abundancia, para sostener gastos de señores pródigos o muy remisos al trabajo. Pero ni siquiera tarde el éxito acompañó mis intentos, de modo que pudiera salir de aquí hacia los lugares deseados, o quedara algo de mis bienes familiares, entre los saqueos a que los sometieron los bárbaros y la impiedad de los romanos, que contra toda ley y en diversos tiempos se lanzaron, con desenfreno, en mi daño. De tal crimen no pueden librarse nombres para mí queridos, lo cual es causa mayor de mi dolor, pues al perjuicio de mis bienes se suma el daño contra mi afecto, el cual sé que debo fielmente a mis parientes cercanos y, aun lastimado, creo que es impío no darlo. Pero, si bien lo sé, ahora debe ser alabada mi suerte, que te agradó, Cristo, porque tú me preparabas cosas mucho mejores que cuando yo estaba más seguro y también pensaba que favorecías nuestros deseos; cuando mi alegre casa florecía en gran abundancia de delicias y mi pompa no era menos, por ese honor que le daban y por el apoyo de multitud de clientes. Me avergüenzo ahora por haber amado cosas tales, que pronto perecerían, y ya viejo conozco, con mejor sentido, que me fueron quitadas por mi bien para que, perdidas las riquezas terrenas y caducas, aprendiera más bien a buscar las que permanecerán eternamente.

39 Per urbes / Argivas atque Epiri veterisque novaeque. Por "argivas" pueden entenderse ciudades de la Argólida o también de toda Grecia. El segundo sentido es el que da Evelyn White: "of Greece". En cuanto al Epiro, era una región de Grecia Continental sobre el mar Jónico. Por Epirus Nova se entendía la región llamada por los romanos Illyricum. 
Tarde por cierto pero nada es tarde para ti nunca, Dios mío, que no tienes fin y a tu misericordia no pones fin; y sabes socorrer a los ignorantes solos, anticipándote primero al deseo de muchos que te ruegan y previendo para nosotros bienes más allá de lo que te pedimos; y a los dudan en aquello que ruega cada uno para sí, les niegas muchas cosas pedidas, más dispuesto a dar lo mejor a quienes anteponen tus dones a sus deseos. Pues al ser yo entregado ${ }^{40}$ probaste cuánto mejor que yo mismo me conocías a mí y a mis costumbres, puesto que osaba cosas que eran superiores a mis fuerzas; con todo, esto lo previste tú y dispusiste las cosas mejor para mí, conteniéndome en mis altos intentos. En mi audacia trataba de vivir de la manera perfecta de un monje, aunque mi casa estaba llena de mis queridos afectos, que podían reclamar se les guardara el acostumbrado cuidado: mis hijos, mi madre, mi suegra, mi esposa, con una grey no pequeña de servidoras; y exponerla toda al mismo tiempo a tierra extraña no lo permitían ni razón ni piedad ni tampoco una mente religiosa. Pero tu mano divina y tu poder providente me dirigió para que obrara el consejo de los santos, que entonces me persuadían a guardar la antigua costumbre, la cual, una vez introducida por la tradición de mis mayores, entonces también nuestra Iglesia mantenía y guardaba. Así confesé lo que sabía necesitaba mi arrepentimiento y me propuse vivir atado por la ley propuesta, quizás expiando mis faltas con un esfuerzo no digno (si bien yo mismo sabía guardar la recta fe) porque aprendía las vías del error a través de las perversas doctrinas, ${ }^{41}$ que ahora repruebo, unidas también a las otras culpas. Mas luego, una vez pasado el quinto trienio, volviendo la Pascua en el tiempo prescripto, volví, Cristo Dios, hasta tus sagrados altares y, gracias a tu misericordia,

40 In me prodendo. En mi opinión el sentido es: al ser yo entregado a mi destino, a tu providencia, pues cuando aspiraba a cosas que habrían sido inconvenientes para los míos, lo impediste (conatus inhibendo meos, v. 455).

41 Según Evelyn White, durante el período en que Paulino estuvo "performing some form of penance", los dogmata prava eran probablemente arrianos. 
recibí lleno de gozo tus sacramentos, antes de estos treinta y ocho años pasados. A salvo estaba entonces el orden de mi propia casa, la cual hasta poco antes se había mantenido y que ya había visto que no podía 480 abandonar, ni tampoco mantener, pues mis riquezas extranjeras estaban reducidas. Mi esposa me impidió que intentara recuperar mi propiedad, de cuyo valor y ubicación recuerdo haber hablado antes; pues ella era muy poco dócil para plegarse a los beneficios comunes y rehusaba, por su gran temor, navegar. Consideraba que no podía llevarla a disgusto; pero no era menos injusto que yo le sacara los hijos y que la abandonara. Y así, frustrado en mis mejores esperanzas de gozar del reposo en mis propiedades, después de muchas adversidades, paso un perpetuo exilio en la variada suerte de mis días, ya hace tiempo carente de todos mis afectos, primero de mi suegra y de mi madre, luego de mi difunta esposa, de quien, aun contraria a mis deseos, por sus temores, me dolí a su muerte, pues me fue quitada cuando hubiera podido ser más que nunca, unida a mí, consuelo en la vejez; esos consuelos ya me habían faltado al irse mis hijos, no con los mismos deseos ni en el mismo tiempo, pero con el ardor de la libertad, que pensaban podían en mayor medida encontrar ellos estando en Burdeos, si bien compartiendo la suerte con colonos godos. Aunque me dolía de que sus deseos se opusieran a los míos, consideraba una compensación el que el cuidado de los presentes atendiera los intereses del ausente, pues participaban espontáneamente del fruto de nuestros bienes, cualesquiera fuesen. Pero pronto una muerte repentina me quitó uno, ya un joven presbítero, ${ }^{42}$ y me dejó amargo luto, y la totalidad de mis bienes que él tenía me fue griega presbíteros significa "más viejo". 
arrebatada enteramente por la rapiña de muchos. Además también él, el que me había quedado como consuelo, a la vez por acciones y azares siniestros ${ }^{43}$ entre las amistades y las iras del rey, ${ }^{44}$ perdió casi todos mis bienes, con suerte parecida. Así, quitada toda esperanza de consuelos, que yo pensaba podía tocarme de parte de los nuestros, y entendiendo, aun tarde, que lo que deseamos debe venir más bien de ti, Dios bueno, en quien está el sumo poder, de a poco decidí establecerme en Marsella, ciudad en que tenía muchos santos queridos, si bien un pequeño patrimonio familiar. Ya no tenía una gran esperanza en nuevos frutos ni campo labrado por sus agricultores; no tenía viñedos: pues solo de ellos se valía la ciudad para poder procurarse todo sustento de su vida. Solo tenía una casa en la ciudad, con su huerto próximo, y un pequeño campito que era refugio de mi privacía, con vides y frutos mas sin tierra digna de cultivar; pero los gastos de mi exigua tarea me persuadieron a cultivar el terreno vacío, - apenas cuatro yugadas ${ }^{45}$ enteras de un consumido campo - y levanté una casa en lo alto del peñasco, para no parecer acortar algo del espacio de tierra. Pero los gastos que mi vida requería yo esperaba afrontarlos gracias a los alquileres de mis campos, mientras mi casa permaneció llena de esclavos y mi edad mejor me conservó mayores fuerzas. Mas no bien esta decayó y ambas condiciones, siempre inestables, de mi vida cambiaron, poco a poco - así lo admito - vencido por los cuidados y años, desterrado, sin recursos ni seres queridos, rápido tomé nueva decisión y, vacilante frente a diversas razones, creí mejor dirigirme a Burdeos. Pero mis esfuerzos no consiguieron resultado,

43 Actu simul eventuque sinistro. Sinister como "desafortunado". 44 Se refiere a Ataúlfo, de quien se habló en v. 343 et seq. 45 Cada yugada era aproximadamente $2500 \mathrm{~m}^{2}$. 
aunque el provecho ayudó a sus propios deseos. Es justo que crea, oh Cristo mío, que todo esto había sido previsto por ti para confirmar mi fe, para que yo poco a poco experimentara cuánto era la que podía darme tu gracia; pues si bien vi arruinado mi patrimonio ante tantas pérdidas, veía al menos perdurar el aspecto de mi casa, con sus medios renovados por tu providencia. ${ }^{46}$ Por esta suerte de vida, Dios mío, sé que te debo innúmeras gracias, pero en cuanto a mí mismo no sé si puedo alegrarme con mi pudor a salvo pues, por ocupar una casa en apariencia propia o por contentarme con ceder a mis hijos, ricos, todo lo que podía aún ser considerado nuestro, me resigno a sustentarme con recursos ajenos; pero nos socorre la fe, que nos enseña que nada es propio; de modo de poder valerme de lo ajeno como nuestro y de estar obligado a dar a otros. $\mathrm{Y}$ en este mismo curso de mi vida no permitiste que vacilara en dudas, y espontáneamente, Dios, te dignaste consolarme. En tu constante hábito de aliviar nuestra vejez, débil por las diversas enfermedades de varios tiempos, con remedios suaves me otorgaste ahora también rejuvenecer. Me demostraste que ya no podría esperar ningún fruto de los bienes que venían de mis ancestros; todo aquello que, ya empobrecido, pude poseer en Marsella lo tenía, perdida ya la propiedad, bajo título de condición escrita; y me enviaste en esos momentos un comprador desconocido, de origen godo, que quería comprar el campito en mi poder y dio espontáneamente un precio. No era este justo, lo admito, pero sí apropiado a mis deseos, y con él pude afirmar las antiguas

46 Al parecer, como dice a continuación, Paulino vivió en Burdeos nuevamente en su casa, la cual estaba en poder de hijos suyos; dice Evelyn White que probablemente se trataba de hijos menores, distintos que aquellos que habían muerto y el poeta mencionaba en v. 498 et seq. 
ruinas de mis caídos recursos y, a la vez, evitar otros nuevos daños al honor, apreciado para mí. Alegrándome por este notable don, omnipotente Dios, te debo a ti nuevas gracias, que sobrepasan casi todas las otras y se juntan a las anteriores que la actual página testimonia. Y por más que ella se ha extendido por amplios espacios y casi ya está pidiendo que se le dé un término, no sabe sin embargo nuestra devoción poner fin, Cristo, al reconocimiento de todos tus dones. Pero solo de esto soy consciente como bien; deseo esto solo mantener; solo deseo con todo mi corazón constantemente en todo lugar y tiempo mostrarte a ti al hablar y recordarte en mi silencio. Y como yo y todas mis cosas nos debemos enteramente a ti, óptimo Dios, y como empecé esta mi obra desde ti, ahora también la voy a concluir en ti. Y te ruego más atenta e insistentemente ahora que (como en esta vida senil que ahora paso no puedo temer nada más que la propia muerte ni me es fácil discernir qué es lo que deseo más), sea donde sea que se dirijan tus juicios, dame, te ruego, una mente intrépida ante toda tristeza y hazla constante, gracias al don de tu fortaleza; para que yo, que ya hace tiempo estoy dedicado a tus leyes y busco llegar a la salud prometida, 605 no tema demasiado los tiempos de la muerte, más cercanos en razón de mi vejez (a la muerte se somete toda edad); que no me agiten a mí, por miedo ante lo incierto de la vida, los azares varios que sé pueden evitarse, Dios, con tu guía. Más bien, cualquiera sea la suerte que aguarda a mi fin, que la esperanza de verte la mitigue, y que aleje todo dudoso pavor la confianza en que, mientras persisto en mi propio cuerpo mortal, soy tuyo: tuyo es todo. Ya disuelto, sé que estaré en cualquier parte de tu cuerpo. 